\title{
Reversal of the Warburg effect with DCA in PDGF-treated human PASMC is potentiated by pyruvate dehydrogenase kinase-1 inhibition mediated through blocking Akt/GSK-3ß signalling
}

\author{
BINGBING LI $^{1 *}$, YULING ZHU $^{1 *}$, QING SUN $^{1}$, CHUNFANG YU $^{1}$, LIAN CHEN $^{1}$, YALI TIAN $^{1}$ and JIE YAN \\ ${ }^{1}$ Department of Anaesthesiology, Nanjing Drum Tower Hospital, \\ The Affiliated Hospital of Nanjing University Medical School, Nanjing, Jiangsu 210008; \\ ${ }^{2}$ Department of Anaesthesiology, The Affiliated Obstetrics and Gynaecology Hospital of Nanjing Medical University, \\ Nanjing Maternity and Child Health Care Hospital, Nanjing, Jiangsu 210004, P.R. China
}

Received January 25, 2018; Accepted June 25, 2018

DOI: $10.3892 /$ ijmm.2018.3745

\begin{abstract}
There is accumulating evidence indicating that the growth inhibitory effect of dichloroacetate (DCA) on pulmonary arterial smooth muscle cells (PASMCs) may be associated with the reversal of the Warburg effect and initiation of the mitochondria-dependent apoptotic pathway. Previous studies indicated that platelet-derived growth factor (PDGF) promoted the Warburg effect and resulted in apoptotic resistance of PASMCs, which was attributed to
\end{abstract}

Correspondence to: Dr Bingbing Li, Department of Anaesthesiology, Nanjing Drum Tower Hospital, The Affiliated Hospital of Nanjing University Medical School, 321 Zhongshan Road, Nanjing, Jinagsu 210008, P.R. China

E-mail: icecolor@163.com

Dr Jie Yan, Department of Anaesthesiology, The Affiliated Obstetrics and Gynaecology Hospital of Nanjing Medical University, Nanjing Maternity and Child Health Care Hospital, 123 Tianfei Avenue, Nanjing, Jiangsu 210004, P.R. China

E-mail: 14751844517@163.com

*Contributed equally

Abbreviations: DCA, dichloroacetate; PASMCs, pulmonary arterial smooth muscle cells; HK-2, hexokinase-2; GSK-3 $\beta$, glycogen synthase kinase-3 $\beta ; \Delta \Psi \mathrm{m}$, mitochondria membrane potential; HIF-1 $\alpha$, hypoxia inducible factor- $1 \alpha$; PAH, pulmonary arterial hypertension; PDH, pyruvate dehydrogenase; PDK, pyruvate dehydrogenase kinase; VDAC, voltage dependent anion channel; PI3K, phosphatidylinositol 3-kinase; FBS, foetal bovine serum; JC-1, 5,5',6,6'-tetrachloro-1,1',3,3'-tetraethylbenzimidazol-carbocyanine iodide

Key words: apoptosis, dichloroacetate, pyruvate dehydrogenase kinase-1, phosphatidylinositol 3-kinase/protein kinase B/glycogen synthase kinase-3 $\beta$, hypoxia inducible factor- 1 , hexokinase-2 activation of the phosphatidylinositol 3-kinase (PI3K)/protein kinase B (Akt) signalling pathway. However, the mechanism underlying the pro-apoptotic effect of DCA on PDGF-treated PASMCs has not been thoroughly elucidated, and the effect of the Akt/glycogen synthase kinase-3 $\beta$ (GSK-3 $\beta$ ) pathway inhibition concomitant with the effect of DCA on PASMC proliferation remains unclear. The growth of human PASMCs and the lactate concentration in extracellular medium of PASMCs were detected by Cell Counting Kit- 8 assays and a Lactate Colorimetric Assay kit, respectively. Cell apoptosis was evaluated by fluorescence activated cell sorting. The mitochondrial membrane potential $(\Delta \Psi \mathrm{m})$ was assessed with 5,5',6,6'-tetrachloro-1,1',3,3'-tetraethylbenzimidazol-carbocyanine iodide assays. The expression levels of phosphorylated Akt and GSK-3 $\beta$, pyruvate dehydrogenase, cleaved caspase-3, pyruvate dehydrogenase kinase-1 (PDK-1), hypoxia inducible factor- $1 \alpha(\mathrm{HIF}-1 \alpha)$ and hexokinase-2 (HK-2) were measured with western blot analysis. Confocal analyses were employed to determine HK-2 co-localisation with the mitochondria. The results indicated that DCA inhibited human PASMC proliferation in a dose-dependent manner. DCA at $10 \mathrm{mM}$ promoted apoptosis and the upregulation of activated caspase- 3 in PASMCs pre-treated with $20 \mathrm{ng} / \mathrm{ml}$ PDGF-homeodimer BB (BB). Treatment with $5 \mu \mathrm{M}$ LY294002 produced minimal anti-proliferative effects on human PASMCs and barely induced cellular apoptosis and caspase-3 activation. However, co-administration of 10 mM DCA with LY294002 significantly decreased the cell proliferation index and induced cell apoptosis and caspase-3 activation. The combined administration of LY294002 with DCA significantly decreased lactate concentration, promoted the depolarisation of the $\Delta \Psi \mathrm{m}$ and repressed HIF-1 $\alpha$ upregulation and HK-2 activation in PASMCs treated with PDGF, which was attributed to the potentiation of DCA-induced PDK-1 inhibition by LY294002 via blockade of the Akt/GSK-3 $\beta / \mathrm{HIF}-1 \alpha$ signalling pathway. In conclusion, inhibition of the Akt/GSK-3 $\beta$ pathway improved the pro-apoptotic effect of DCA on human PASMCs, which may be attributed to a reversal of the Warburg effect by 
blocking the mutual interaction between HIF-1 $\alpha$ and PDK-1, consequently downregulating HK-2. Therefore, combinatory treatment with DCA and PI3K inhibitors may represent a novel therapeutic strategy for the reversal of apoptosis resistance exhibited by PASMCs as a result of mitochondrial bioenergetic abnormalities, as well as the treatment of pulmonary vascular remodelling in pulmonary arterial hypertension.

\section{Introduction}

Hyperplasia and phenotypic remodelling of pulmonary arterial smooth muscle cells (PASMCs) serve key roles in the progressive narrowing and occlusion of the distal pulmonary arterioles in pulmonary arterial hypertension (PAH) $(1,2)$. As in cancer cells, mitochondria from proliferating PASMCs may undergo diverse molecular changes and respond by switching their cellular metabolism towards cytoplasm-based glycolysis, a condition associated with apoptosis resistance $(3,4)$. Previous studies indicated that platelet-derived growth factor (PDGF) expression was increased in neointimal lesions of rats treated with hypoxia or monocrotaline; the application of a tyrosine receptor inhibitor, imatinib, exhibited a beneficial effect in abrogating these pulmonary vasculature lesions $(5,6)$. Previous results from Xiao et al (7) suggested that PDGF promoted the Warburg effect, which refers to enhanced glycolysis effects under normoxic conditions, and induced excessive proliferation and apoptosis resistance in PASMCs (8). The activation of the phosphatidylinositol 3-kinase (PI3K)/protein kinase B (Akt) signalling pathway accounted for this transition in metabolic phenotype (glucose oxygenation to glycolysis), as pharmacological ablation of PI3K with LY294002 facilitated the reversal of the Warburg effect (7).

Dichloroacetate (DCA), a selective inhibitor of pyruvate dehydrogenase kinase-1 (PDK-1), activates pyruvate dehydrogenase $(\mathrm{PDH})$, which catalyses the decarboxylation of pyruvate into acetyl-CoA, promoting substrate entry into the Krebs cycle. DCA-mediated inhibition of PDKs triggers a switch in pyruvate metabolism towards glucose oxidation to $\mathrm{CO}_{2}$ in mitochondria, along with a destabilisation of hypoxia-inducible factor- $1 \alpha$ (HIF-1 $\alpha)$, which reverses the hyper-polarised mitochondrial membrane potential $(\Delta \Psi \mathrm{m})$ and induces apoptosis of cancer cells (3). DCA also has beneficial effects on PAH due to its 'lung selective' characteristic and ameliorates pulmonary vascular remodelling in several rodent models of PAH (9-11). The reversal of HIF-1 $\alpha$ activation and the Warburg effect is considered to serve a pivotal role in mitigating the vascular lesions in rats subjected to carotid intimal balloon injury (12). Furthermore, the hypoxia response element is ubiquitously present in the promoter regions of genes encoding glycolytic enzymes, including PDK-1, glucose transporter-1 and hexokinase (13). Hexokinases (HKs) catalyse the first essential step in glucose metabolism by phosphorylation of glucose to glucose-6-phosphate. There are 4 major isoforms (HK-1, HK-2, HK-3, and HK-4) characterised in mammalian tissue (14). Among these, HK-2 has been extensively investigated and identified to be associated with a blocking of cytochrome $c$ release through the induction of the pro-apoptotic proteins B-cell lymphoma 2 (Bcl-2)-associated $\mathrm{X}$ protein and BH3 interacting-domain death agonist, and protection of cancer cells from apoptosis (15). The interaction between HIF-1 $\alpha$ and HK-2 in cancer cells is well-documented yet poorly exploited in vascular cells $(16,17)$. A study by Lambert et al (12) indicated that the hyper-proliferating smooth muscle cells (SMCs) from injured carotid arteries exhibited activation of HIF-1 $\alpha$ and HK-2 and increased glycolysis. Functional suppression using small interfering RNA (siRNA) targeting HIF- $1 \alpha$ promoted SMC apoptosis through the inhibition of HK-2 expression and translocation of HK-2 with voltage dependent anion channel (VDAC) on the outer membrane of the mitochondria (12). Additionally, HK-2 was identified to be upregulated in neointimal lesion regions in pre-capillary pulmonary arterioles in a rat model of severe PAH, accompanied by a high expression of HIF-1 $\alpha$ (18). In addition to the transcriptional regulation of HK-2 by HIF-1 $\alpha$, HK-2 expression is precisely controlled by multiple signalling pathways, particularly the PI3K/Akt/glycogen synthase kinase-3 $\beta$ (GSK-3 $\beta$ ) axis (19). A study by Bonnet et al (20) indicated that dehydroepiandrosterone, a steroid hormone, decreased proliferation and induced apoptosis of vessel SMCs in vivo and in vitro, which was mediated by inhibition of Akt /GSK-3 $\beta$, interfering with the HK-2/VDAC interaction.

In the present study, whether PDK-1 and HK-2 inactivation was involved in DCA-induced growth retardation and whether the pro-apoptotic effect of DCA in PASMCs exposure to PDGF was potentiated by blocking the PI3K/Akt signalling pathway were investigated. The results of the present study revealed that DCA induced a pro-apoptotic effect on human PASMCs associated with the downregulation of PDK-1 and HIF- $1 \alpha$ and subsequent HK-2 inactivation via blocking of the mitochondrial interaction. Furthermore, this effect may be potentiated via the suppression of PDK-1 by blocking the Akt/GSK-3 $\beta / \mathrm{HIF}-1 \alpha$ signalling pathway.

\section{Materials and methods}

Ethics approval. The present study was approved by the Ethics Committee of Nanjing University Drum Tower Hospital for Institutional Animal Care and Use.

Cell culture. Human PASMCs were purchased from Wuxi BioHermes Biomedical Technology Co., Ltd (Wuxi, China). They were trypsinised and subcultured subsequent to reaching $90 \%$ confluence. A monoclonal antibody against smooth muscle $\alpha$-actin (1:1,000; cat. no. M085129-2; Agilent Technologies, Inc., Santa Clara, CA, USA) was used to assess the purity $(>99 \%)$ of the SMC culture according to the manufacturer's protocol. Unless otherwise indicated, primary cultures of PASMCs were maintained in RPMI-1640 containing 10\% foetal bovine serum (FBS) and $1 \%$ antibiotics (penicillin and streptomycin mixture), all purchased from Thermo Fisher Scientific Inc. (Waltham, MA, USA).

All experiments examining HK-2, HIF-1 $\alpha$ activation, Akt, GSK-3 $\beta$, PDH phosphorylation and PDH kinase-1 (PDK-1) expression, and cell viability analysis, were performed on cells that were cultured for 3 days at passages 3-5. Following this, cells were trypsinised and seeded at a distinct cell density into 96-well plates (5,000 cells/well) or culture flasks $\left(5 \times 10^{5}\right.$ cells/flask) and subcultured in RPMI-1640 containing $10 \% \mathrm{FBS}$ and $1 \%$ antibiotics in a humidified $5 \% \mathrm{CO}_{2}$ atmosphere at $37^{\circ} \mathrm{C}$ overnight. Cells were then exposed to 
PDGF-BB (Cytolab Ltd., Rehovot, Israel), SB216763 (S1075; Selleck Chemicals, Houston, TX, USA), DCA (5, 10, 20 and $50 \mathrm{mM}$ ) and LY294002 (Sigma-Aldrich; Merck KGaA, Darmstadt, Germany) at numerous concentrations $(5,10$ and $20 \mu \mathrm{M})$ or a combination of two drugs (10 mM DCA and $5 \mu \mathrm{M}$ LY294002) as indicated. In the control groups, an equal volume of PBS was substituted for the reagents.

Determination of cell viability [Cell-Counting-Kit 8 (CCK-8) colorimetric assay]. Cells were seeded at 5,000 cells/well into 96-well plates and grown in RPMI-1640 supplemented with $10 \%$ FBS for $72 \mathrm{~h}$. After $48 \mathrm{~h}$ of serum starving with $0.5 \%$ FBS, the cells were then incubated with $20 \mathrm{ng} / \mathrm{ml}$ PDGF, followed by increasing concentrations of DCA $(5,10,20$ and $50 \mu \mathrm{M}), \mathrm{LY} 294002$ or a combination of the two drugs for $72 \mathrm{~h}$. Following drug exposure, cells were incubated in a humidified $5 \% \mathrm{CO}_{2}$ atmosphere at $37^{\circ} \mathrm{C}$ with $10 \mu \mathrm{l} \mathrm{CCK}-8$ (Dojindo Molecular Technologies, Inc., Kumamoto, Japan) for $1 \mathrm{~h}$. The optical densities in the 96-well plates were determined using a microplate reader at a wavelength of $450 \mathrm{~nm}$. The cell proliferation percentage was determined in the treated (AT), PDGF (Ap), blank (Ab) groups using the following formula: Proliferation Index $=(\mathrm{AT}-\mathrm{Ab} / \mathrm{Ap}-\mathrm{Ab}) \times 100$; optical density was measured at a $450 \mathrm{~nm}$ wavelength.

Cell apoptosis and 5,5',6,6'-tetrachloro-1,1',3,3'-tetraethylbenzimidazol-carbocyanine iodide (JC-1) assays. Cells were seeded in $25 \mathrm{~cm}^{2}$ tissue culture flasks at $5 \times 10^{5}$ cells/flask and incubated in standard conditions. Cells were maintained in complete medium for $16 \mathrm{~h}$, followed by serum starvation for $24 \mathrm{~h}$ prior to treatment with $20 \mathrm{ng} / \mathrm{ml}$ PDGF with $5 \mu \mathrm{M}$ LY294002, DCA at $10 \mathrm{mM}$, a combination of LY294002 and $10 \mathrm{mM}$ DCA or alone for $48 \mathrm{~h}$. Following drug treatment, PASMCs were harvested and centrifuged at $4^{\circ} \mathrm{C}$ at $600 \mathrm{x} \mathrm{g}$ for $5 \mathrm{~min}$; the pellets were washed twice with PBS and then resuspended in $100 \mu \mathrm{l}$ Annexin $\mathrm{V}$ binding buffer $(0.14 \mathrm{M}$ $\mathrm{NaCl}, 2.5 \mathrm{mM} \mathrm{CaCl}$, 0.01 M HEPES pH 7.4). Annexin V (1 $\mu \mathrm{l}$; Invitrogen; Thermo Fisher Scientific, Inc.) and $5 \mu 1$ propidium iodide $(50 \mu \mathrm{g} / \mathrm{ml})$ were added to the samples and incubated at room temperature in the dark for $15 \mathrm{~min}$. Samples were kept on ice following incubation until fluorescence activated cell sorting (FACS) analysis was performed. For the assays measuring mitochondrial membrane potential $(\Delta \Psi \mathrm{m})$, the cells were treated as indicated above, and then $1 \mu \mathrm{l} \mathrm{JC}-1$ (Beyotime Institute of Biotechnology, Haimen, China) was added in the medium at a final concentration of $2 \mu \mathrm{M}$, and the cells were stained at room temperature for $30 \mathrm{~min}$ in the dark. Subsequent to JC-1 staining, cells were trypsinised, washed twice with PBS and resuspended in $100 \mu 1$ PBS. JC-1 fluorescence intensity was examined using FACS and data was analysed with FlowJo 7.61 software (Tree Star Inc., Ashland, OR, USA).

Lactate measurement. The PASMCs were seeded into $25 \mathrm{~cm}^{2}$ tissue culture flasks at a cell density of $5 \times 10^{5}$ cell/flask and cultured with RPMI-1640 complete culture medium for $16 \mathrm{~h}$ followed by serum starvation with $0.5 \%$ FBS for $24 \mathrm{~h}$. The cells were then incubated at $37^{\circ} \mathrm{C}$ with $20 \mathrm{ng} / \mathrm{ml}$ PDGF with $5 \mu \mathrm{M}$ LY294002, DCA at 10 or $20 \mathrm{mM}$, a combination of LY294002 and $10 \mathrm{mM}$ DCA, or alone for $48 \mathrm{~h}$, subsequent to which the medium was removed from cells and lactate levels in the extracellular medium were measured at room temperature using the Lactate Colorimetric Assay kit (Abcam, Cambridge, MA, USA) according to the manufacturer's protocol. Lactate concentration was normalised to sample cell number.

Immunoblotting and densitometric analysis. The PASMCs were seeded into T25 culture flasks at a cell density of $1 \times 10^{6}$ and cultured with RPMI-1640 complete culture medium for $16 \mathrm{~h}$ followed by serum starvation with $0.5 \%$ FBS for $24 \mathrm{~h}$. Thereafter, the cells were incubated under different interventions for $24 \mathrm{~h}$, as aforementioned, while PBS was substituted for reagents in control cells cultured in medium with $0.5 \%$ FBS. Immunoblotting was performed as described previously (18). Briefly, PASMCs were harvested and resuspended in ice-cold cell lysis solution (Thermo Fisher Scientific, Inc.) and the homogenate was centrifuged at $400 \mathrm{x}$ g for $15 \mathrm{~min}$ at $4^{\circ} \mathrm{C}$. Protein concentration was determined using a Bicinchoninic Acid Protein Assay kit (cat. no. PICPI23223; Thermo Fisher Scientific, Inc.). The supernatant was subsequently transferred to a fresh tube and $75 \mu \mathrm{g}$ protein from each sample was then separated via $12 \%$ SDS-PAGE. Following this, the proteins were then transferred to polyvinylidene difluoride membranes. Membranes were then blocked using 5\% fat-free milk for $1 \mathrm{~h}$ at room temperature and subsequently incubated at $4^{\circ} \mathrm{C}$ overnight with the following primary antibodies specific to Akt, phosphorylated (p)-Akt, GSK3 $\beta$, p-GSK3 $\beta$ (Cell Signaling Technology, Inc., Danvers, MA, USA; cat. nos., 4685, 4060, 9315 and 9313, respectively), HK-2, PDK-1 (1:1,000; Cell Signaling Technology, Inc.; cat. nos., 2867 and 3820), phospho(S293)-PDH E1 $\alpha$ subunit (1:1,000; Abcam, Cambridge, UK; cat. no., ab177461), HIF-1 $\alpha$ (1:500; Novus Biologicals, LLC, Littleton, CO, USA; cat. no., NB100-449) and $\beta$-actin (1:2,000; Santa Cruz Biotechnology, Inc., Dallas, TX, USA; cat. no., sc-47778). Following this, membranes were incubated for $2 \mathrm{~h}$ at room temperature with the following secondary antibodies: Horseradish peroxidase-conjugated goat anti-rabbit IgG (cat. no. ab6721; 1:5,000; Abcam) or HRP-conjugated anti-mouse IgG (cat. no. 5450-0011; 1:5,000; KPL, Gaithersburg, MD, USA). $\beta$-actin protein expression served as an internal control and was used to normalise the protein band intensity. To determine the phosphorylation levels of AKT and GSK-3 $\beta$, membranes was washed with stripping buffer (cat. no. P0025S; Beyotime Institute of Biotechnology) at $50^{\circ} \mathrm{C}$ for $30 \mathrm{~min}$, followed by blocking the membrane with $5 \%$ bovine serum albumin (cat. no. 37525; Thermo Fisher Scientific Inc.) in PBST at room temperature for $4 \mathrm{~h}$. The membrane was then re-probed at $4^{\circ} \mathrm{C}$ overnight with p-AKT $(1: 1,000)$ and $p-G S K-3 \beta$ antibodies $(1: 1,000$; Cell Signalling Technology, Inc., Danvers, MA, USA). Western blots were detected using the Western chemiluminescent detection system (Pierce; Thermo Fisher Scientific, Inc.) and exposure to X-ray film. Images were acquired using a CanoScan $8600 \mathrm{~F}$ flatbed scanner, quantified using ImageJ software (version 1.4; National Institutes of Health, Bethesda, MD, USA) and standardised to $\beta$-actin in each lane. Experiments were repeated in triplicate.

Immunofluorescence confocal microscopy. Human PASMCs were fixed with $1 \%$ paraformaldehyde and permeabilised 

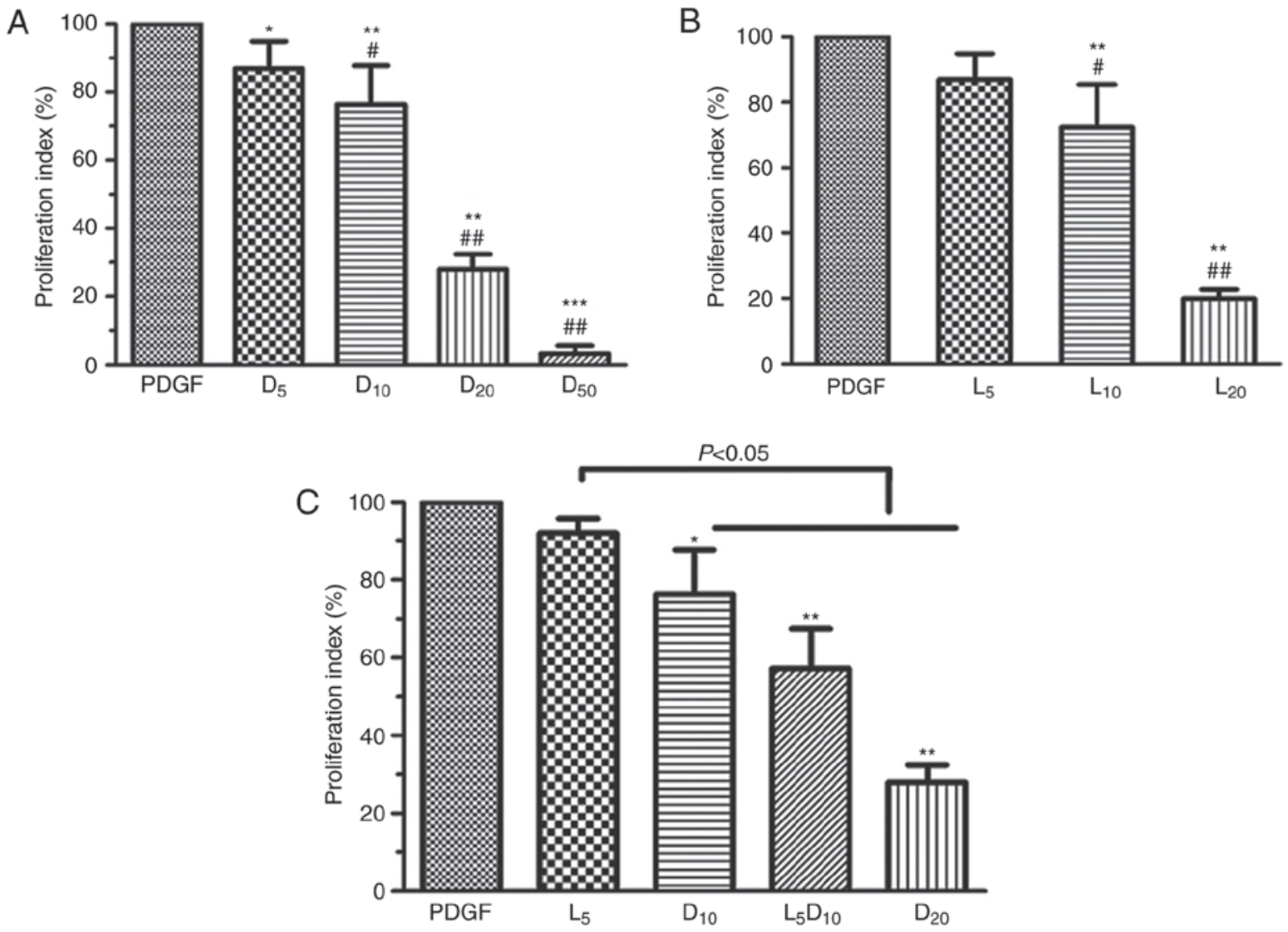

Figure 1. Effect of DCA, LY294002 or combination of DCA and LY294002 on the growth of human PASMCs. The human PASMCs were seeded in 96-well plates in RPMI-1640 medium supplemented with $10 \%$ FBS followed by $48 \mathrm{~h}$ serum starving prior to exposure to $20 \mathrm{ng} / \mathrm{ml}$ PDGF or with increased concentrations of (A) DCA or (B) LY294002 in fresh culture medium with $0.5 \%$ foetal bovine serum for $72 \mathrm{~h} .{ }^{*} \mathrm{P}<0.05,{ }^{* *} \mathrm{P}<0.01$ and ${ }^{* * * *} \mathrm{P}<0.001$ vs. PDGF-treated cells; ${ }^{\#} \mathrm{P}<0.05$ and ${ }^{\# \#} \mathrm{P}<0.01$ vs. cells treated with $5 \mathrm{mM}$ DCA or $5 \mu \mathrm{M}$ LY294002. (C) Cells were exposed to PDGF or $5 \mu \mathrm{M} \mathrm{LY} 294002,10$ or $20 \mathrm{mM}$ DCA and combination of $5 \mu \mathrm{M}$ LY294002 and DCA $(10 \mathrm{mM})$ for $24 \mathrm{~h} .{ }^{*} \mathrm{P}<0.05,{ }^{* *} \mathrm{P}<0.01$ as compared with PDGF cells. The data are presented as the mean \pm standard deviation of 6 duplicated wells in three separate experiments. PASMCs, pulmonary arterial smooth muscle cells; DCA, dichloroacetate; PDGF, platelet-derived growth factor; D5, D10, D20 and D50, cells treated with dichloroacetate at 5, 10, 20, $50 \mathrm{mM}$, respectively, following PDGF exposure. L5, 10 and 20, cells treated with LY294002 at 5, 10, 20 $\mu \mathrm{M}$, respectively, following PDGF exposure. L5D10, cells treated in a combination of $5 \mu \mathrm{M} \mathrm{LY} 294002$ and $10 \mathrm{mM}$ dichloroacetate following PDGF exposure.

with $0.2 \%$ Triton $\mathrm{X}-100$. The $\Delta \Psi \mathrm{m}$ was determined using MitoTracker ${ }^{\circledR}$ Red CMXROS (Invitrogen; Thermo Fisher Scientific, Inc.). The PASMCs were then incubated at $37^{\circ} \mathrm{C}$ with M7512- Mito tracker Red (50 nM) for 30 min and maintained in a dark room at $4^{\circ} \mathrm{C}$ overnight for confocal detection. HK-2 detection was performed using Alexa Fluor $488(10 \mu \mathrm{g} / \mathrm{ml}$; Invitrogen; Thermo Fisher Scientific, Inc.) for green fluorescent protein staining at $37^{\circ} \mathrm{C}$ for $1.5 \mathrm{~h}$. Cell imaging was performed using an FV1000 confocal microscope (magnification, x100) equipped with a live cell apparatus (Olympus Corporation, Tokyo, Japan).

Statistical analysis. Data are presented as the mean \pm standard deviation. Calculations were performed using the GraphPad Prism software package (version 4.0.1; GraphPad Software, Inc., La Jolla, CA, USA), and one-way analysis of variance with Tukey's post-hoc test was applied. $\mathrm{P}<0.05$ was considered to indicate a statistically significant difference.

\section{Results}

DCA inhibits the proliferation of human PASMCs stimulated with PDGF-BB in a dose-dependent manner, which was improved by co-incubation with LY294002. As demonstrated in Fig. 1A, DCA suppressed human PASMC proliferation in a dose-dependent manner (0-50 mM). DCA at $5 \mathrm{mM}$ exhibited minimal inhibitory effects on PASMC proliferation after $72 \mathrm{~h}$ incubation. The cell proliferation index was significantly decreased in the 10,20 and $50 \mathrm{mM}$ groups compared with the $5 \mathrm{mM}$ DCA group $(\mathrm{P}<0.01)$. The inhibitory effect of DCA on the growth of human PASMCs was mimicked by LY294002. LY294002 $(10 \mu \mathrm{M})$ caused a $27.7 \%$ decrease in cell proliferation rate, whereas only a $13.0 \%$ decrease was observed after $72 \mathrm{~h}$ of treatment with $5 \mu \mathrm{M}$ LY294002 (P>0.05; Fig. 1B). Notably, the cell proliferation index was significantly decreased to $57.2 \%$ after $72 \mathrm{~h}$ incubation with a combination of DCA $(10 \mathrm{mM})$ and LY294002 $(5 \mu \mathrm{M})$ compared with the cells treated by DCA alone (76.4\%; P<0.05; Fig. 1C).

Growth inhibitory effect of DCA on PASMCs potentiated by LY294002 may be attributed to increased mitochondriaassociated apoptosis. As indicated in Fig. 2A, the percentage of apoptotic cells was $\sim 18.8 \%$ following treatment with $10 \mathrm{mM}$ DCA, which was significantly increased compared with cells treated with $5 \mu \mathrm{M}$ LY294002 alone $(9.2 \%$; $\mathrm{P}<0.05)$. However, the combined treatment with LY294002 and $10 \mathrm{mM}$ DCA 
A

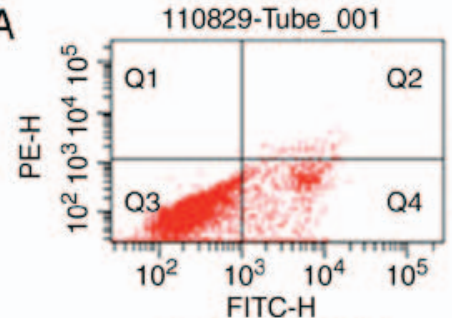

110829-Tube_002

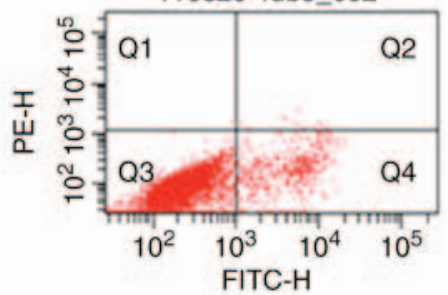

110829-Tube_003

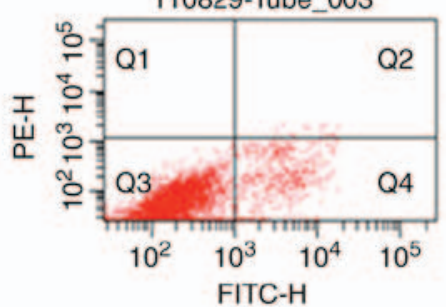

Control

Population \%Parent

\begin{tabular}{rr}
\hline $\mathrm{Q} 1$ & 0.0 \\
\hline $\mathrm{Q} 2$ & 0.6 \\
$\mathrm{Q} 2$ & 91.4 \\
$\mathrm{Q}$ Q4 & 7.9
\end{tabular}

PDGF

Population \%Parent

$\begin{array}{rr}\triangle Q 1 & 0.0 \\ \triangle Q \text { Q2 } & 0.1 \\ \triangle \mathrm{Q} 3 & 93.3 \\ \triangle \mathrm{Q} 4 & 6.5\end{array}$

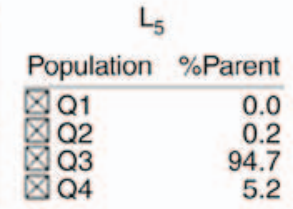

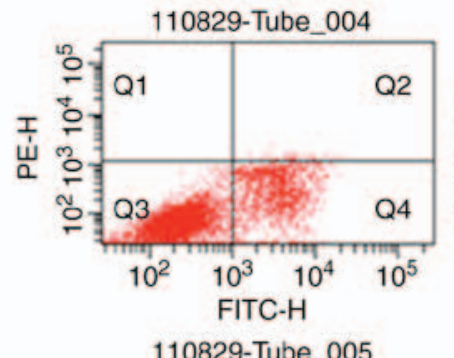

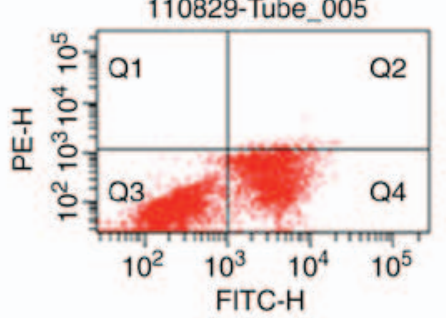

$$
\mathrm{L}_{5} \mathrm{D}_{10}
$$

Population \%Parent

$\begin{array}{rr}\triangle Q 1 & 0.0 \\ \text { Q2 } & 1.0 \\ \text { Q3 } & 55.9\end{array}$

55.9
43.1

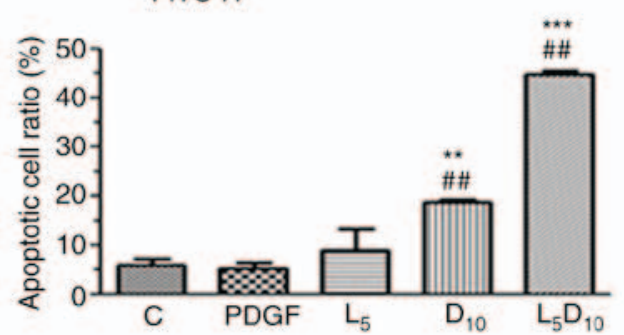

B

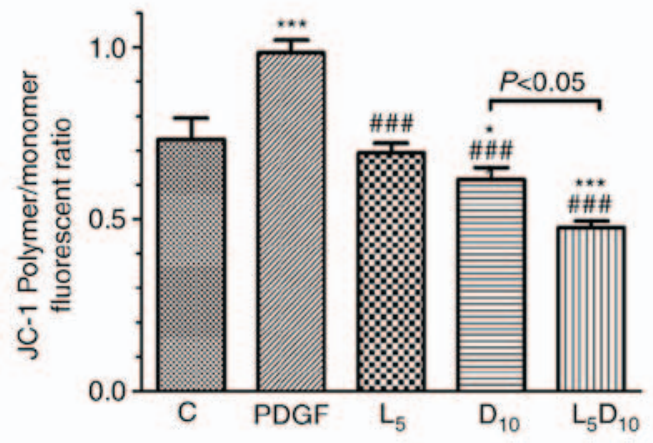

\section{Caspase-3 $35 \mathrm{kDa}$}

Cleaved caspase-3 $17 \mathrm{kDa}$

$\beta$-actin $45 \mathrm{kDa}$

$$
\text { C PDGF } L_{5} \quad D_{10} L_{5} D_{10}
$$
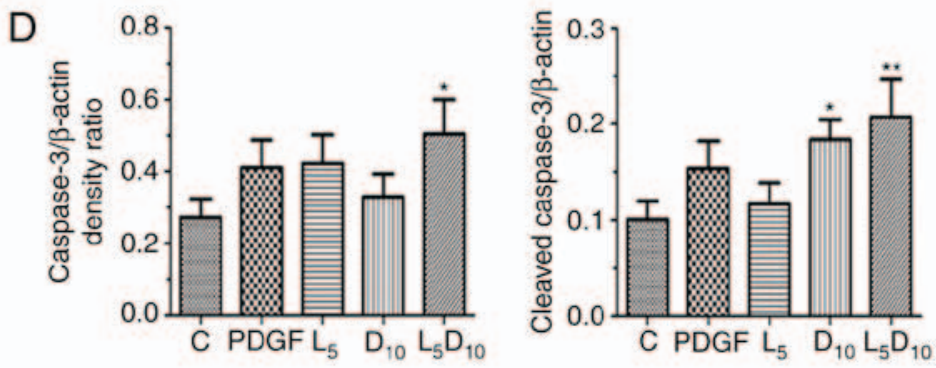

Figure 2. Effect of DCA, LY294002 or combination of DCA and LY294002 on the apoptosis and mitochondria membrane potential of human PASMCs. The PASMCs were seeded into $25 \mathrm{~cm}^{2}$ tissue culture flask at a density of $5 \times 10^{5}$ cell/flask and cultured in RPMI-1640 complete culture medium for $16 \mathrm{~h}$ followed by serum starvation for $24 \mathrm{~h}$. The cells were then exposed to PDGF alone or $5 \mu \mathrm{M} \mathrm{LY} 294002$, DCA at $10 \mathrm{mM}$ or a combination of $5 \mu \mathrm{M} \mathrm{LY} 294002$ and $10 \mathrm{mM}$ DCA for $48 \mathrm{~h}$ prior to (A) apoptosis or (B) JC-1 assay. (C) The expression levels of caspase-3 and cleaved caspase-3 were analyzed with western blot analysis. The representative change of one of the three experiments is presented, as all assays exhibited identical results. (D) Results were pooled from three separate experiments and are presented as mean \pm standard deviation. ${ }^{*} \mathrm{P}<0.05,{ }^{* * *} \mathrm{P}<0.01$ and ${ }^{* * *} \mathrm{P}<0.001$ vs. control cells. ${ }^{\# \#} \mathrm{P}<0.01$ and ${ }^{\# \# \#} \mathrm{P}<0.001$ vs. cells treated with PDGF. C, control; PASMCs, pulmonary arterial smooth muscle cells; DCA, dichloroacetate; PDGF, platelet-derived growth factor; D5 and D10, cells treated with DCA at 5 and $10 \mathrm{mM}$, respectively, following PDGF exposure; L5, cells treated with LY294002 at $5 \mu \mathrm{M}$ following PDGF exposure; L5D10, cells treated with a combination of $5 \mu \mathrm{M} \mathrm{LY} 294002$ and $10 \mathrm{mM}$ DCA following PDGF exposure.

markedly increased the apoptotic cell percentage to $44.9 \%$ following $48 \mathrm{~h}$ incubation. As demonstrated in Fig. 2C and D, although $5 \mu \mathrm{M}$ LY294002 only marginally affected the expression of cleaved caspase-3, it significantly increased cleaved caspase-3 expression levels when added in combination with
$10 \mathrm{mM}$ DCA. The human PASMCs exhibited an increased $\Delta \Psi \mathrm{m}$, following PDGF incubation for $48 \mathrm{~h}$ compared with the control cells $(\mathrm{P}<0.05)$, as expressed by the ratio of red and blue fluorescence intensity following JC-1 staining in Fig. 2B. DCA at $10 \mathrm{mM}$ or LY294002 significantly decreased the $\Delta \Psi \mathrm{m}$ 
A

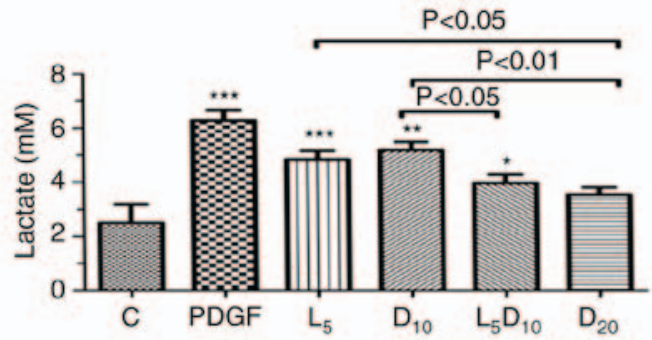

B
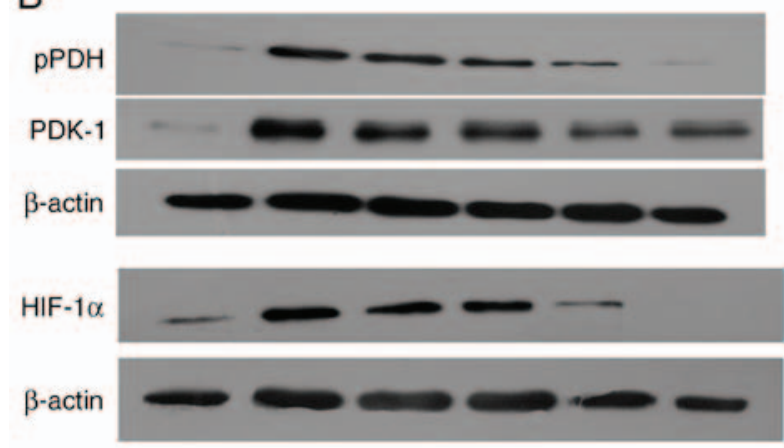

HK-2

$\beta$-actin

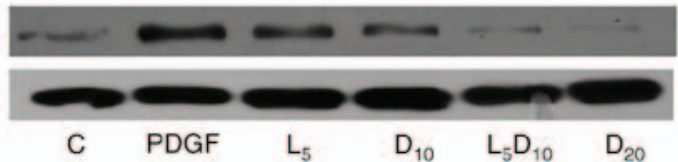

C
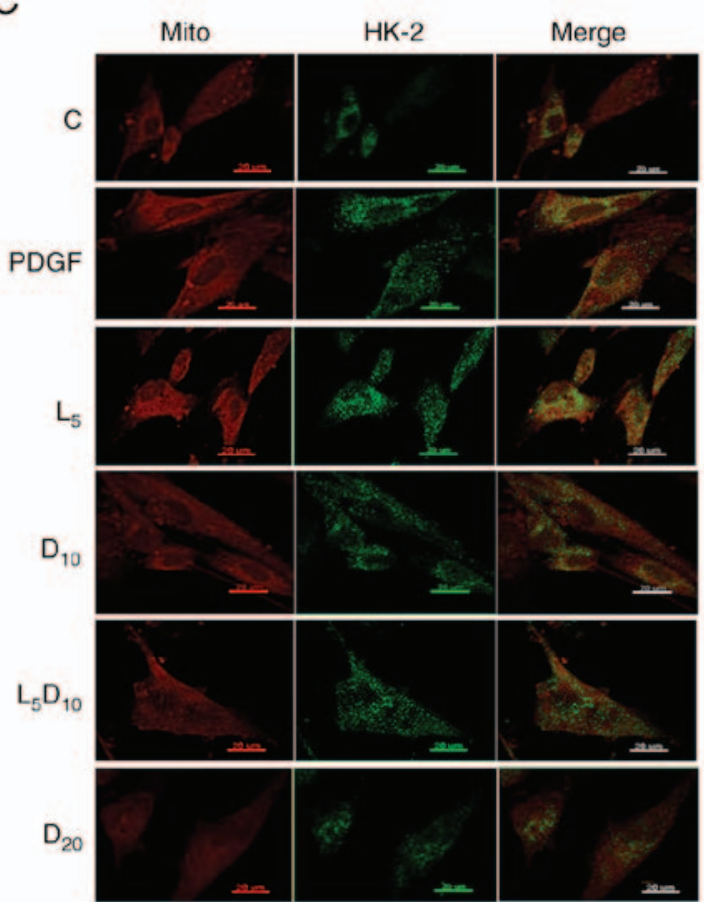

Figure 3. Effect of DCA, LY294002 or combination of DCA and LY294002 on extracellular lactate concentration, key glycolysis-associated enzymes expression and HK-2 activation. The PASMCs were seeded into $25 \mathrm{~cm}^{2}$ tissue culture flask at a density of $5 \times 10^{5}$ cell/flask and cultured with RPMI-1640 complete culture medium for $16 \mathrm{~h}$ followed by serum starvation for $24 \mathrm{~h}$. (A) The cells were then exposed to PDGF or $5 \mu \mathrm{M} \mathrm{LY} 294002$, DCA at 10 or $20 \mathrm{mM}$, and a combination of LY294002 and $10 \mathrm{mM}$ DCA for $48 \mathrm{~h}$ prior to measurement of lactate concentration. ${ }^{*} \mathrm{P}<0.05,{ }^{* * *} \mathrm{P}<0.01$ and ${ }^{* * *} \mathrm{P}<0.001$ vs. control cells. (B) Cell lysates were extracted for PDK-1, PDH, HIF-1 $\alpha$ and HK-2 expression analysis using western blot analysis. The representative change of one of the three experiments is presented, as all assays exhibited identical results. (C) HK-2 activation was analyzed with immune-fluorescent confocal microscopy. PDGF-stimulated PASMCs exhibited significant co-localization between HK-2 (green) and the mitochondria (red), giving a yellow pattern in the merged images. The cells treated with $20 \mathrm{mM}$ DCA and the combination of LY294002 and $10 \mathrm{mM}$ DCA demonstrated diffuse cytoplasmic staining of HK-2 (no colocalization of HK-2 to the mitochondria). C, control; DCA, dichloroacetate; PDGF, platelet-derived growth factor; L5, D10 and D20, cells treated with DCA at 5, 10 and $20 \mathrm{mM}$, respectively, following PDGF exposure; L5, cells treated with LY294002 at $5 \mu \mathrm{M}$ following PDGF exposure; L5D10, cells treated in combination of $5 \mu \mathrm{M}$ LY294002 and 10 mM dichloroacetate following PDGF exposure; PASMCs, pulmonary arterial smooth muscle cells; HK-2, hexokinase-2; PDK-1, pyruvate dehydrogenase kinase-1; PDH, pyruvate dehydrogenase; HIF-1 $\alpha$, hypoxia-inducible factor-1 $\alpha$; mito, mitochondria.

in PASMCs. Furthermore, the $\Delta \Psi \mathrm{m}$ was markedly decreased after $48 \mathrm{~h}$ of treatment with a combination of $10 \mathrm{mM}$ DCA and LY294002 compared with DCA or LY294002 alone $(\mathrm{P}<0.05)$.

Co-treatment with LY294002 and DCA decreases lactate concentration in extracellular culture medium, PDK-1, p-PDH, HIF- $1 \alpha$ and $H K-2$ expression and potentially represses $H K-2$ activation, which are all associated with a reversal of the Warburg effect. As suggested in Fig. 3A, DCA at $10 \mathrm{mM}$ or $5 \mu \mathrm{M}$ LY294002 significantly decreased the lactate concentration in PASMCs stimulated with PDGF-BB. Additionally, the increased concentration of DCA $(20 \mathrm{mM})$ markedly decreased PDGF-induced lactate production (3.55 vs. $6.28 \mathrm{mM}$, respectively; $\mathrm{P}<0.01$ ). The lactate concentration markedly decreased after $48 \mathrm{~h}$ of treatment with the combination of $10 \mathrm{mM}$ DCA and LY294002 compared to $10 \mathrm{mM}$ DCA alone (3.97 vs. $5.18 \mathrm{mM}$; $\mathrm{P}<0.05)$. Furthermore, the upregulation of PDK-1, p-PDH and HIF-1 $\alpha$ induced by PDGF was abrogated by treatment with $10 \mathrm{mM}$ DCA in PASMCs. The inhibitory effect on PDK-1, p-PDH and HIF-1 $\alpha$ expression in PASMCs was improved by a combination of $10 \mathrm{mM}$ DCA with LY294002. The protein expression of HK-2 increased significantly following PDGF treatment compared with the control cells. Treatment with $5 \mu \mathrm{M}$ LY294002 or $10 \mathrm{mM}$ DCA significantly decreased HK-2 expression. The combination of LY294002 and DCA or $20 \mathrm{mM}$ of DCA elicited an additional decrease in HK-2 expression compared with the cells treated with $10 \mathrm{mM}$ DCA (Fig. 3B). In addition, the inhibitory effect of DCA or LY294002 resulted in an uncoupling of HK-2 from the mitochondria. The increased co-localisation of HK-2 with mitochondria in the cytoplasm following PDGF-BB stimulation was significantly attenuated by 10 and $20 \mathrm{mM}$ DCA treatment. Notably, LY294002 increased the dislocation of HK-2 from the mitochondria induced by $10 \mathrm{mM}$ DCA, which is demonstrated clearly in Fig. $3 \mathrm{C}$ as a visible decrease in the yellow fluorescence intensity in the cytoplasm.

Downregulation of PDK-1 through Akt/GSK-3 $\beta$ signal blocking may be involved in the potentiation of DCA-induced human PASMCs apoptosis by LY294002. As indicated in Fig. 4A-D, LY294002 inhibited Akt/GSK-3 $\beta$ axis activation in PASMCs exposed to PDGF-BB in a concentration-dependent manner $(1-20 \mu \mathrm{M})$. The PDK-1 upregulation induced by PDGF in PASMCs was apparently inhibited by LY294002 in a concentration-dependent manner $(1-20 \mu \mathrm{M})$, as demonstrated in Fig. 4E and $\mathrm{F}(\mathrm{P}<0.05)$. To investigate the role of the Akt/GSK-3 $\beta$ axis 
A

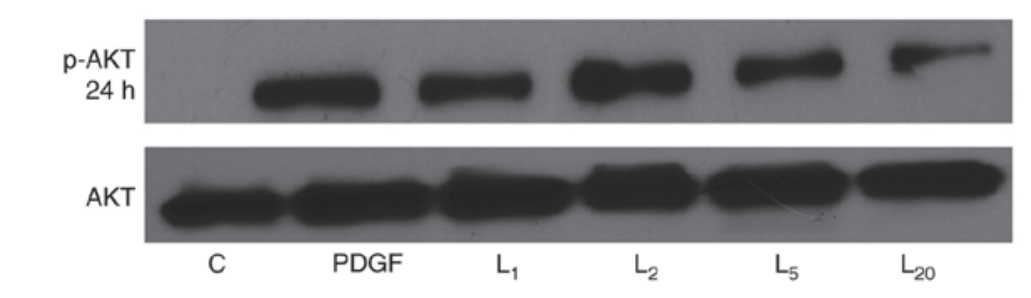

C

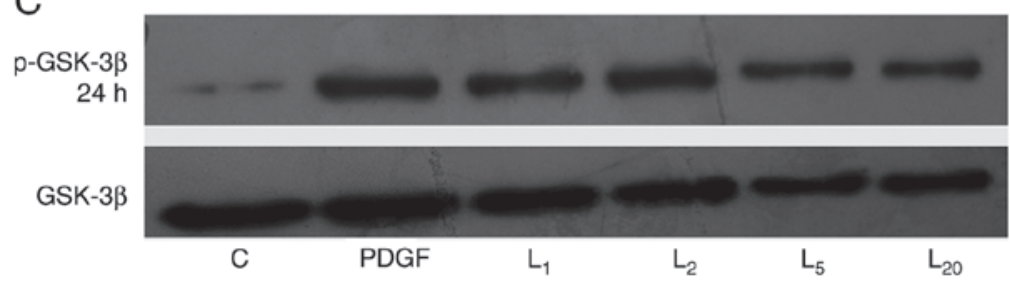

E

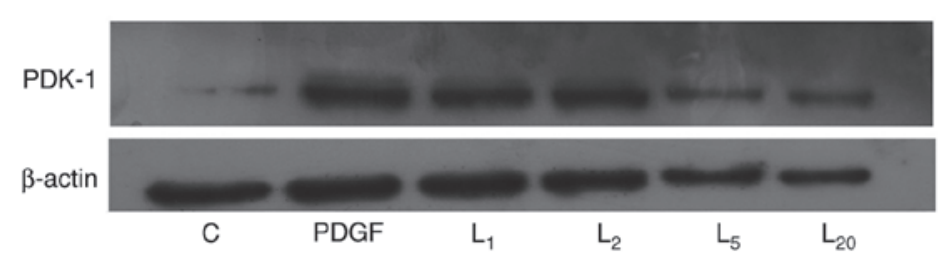

G

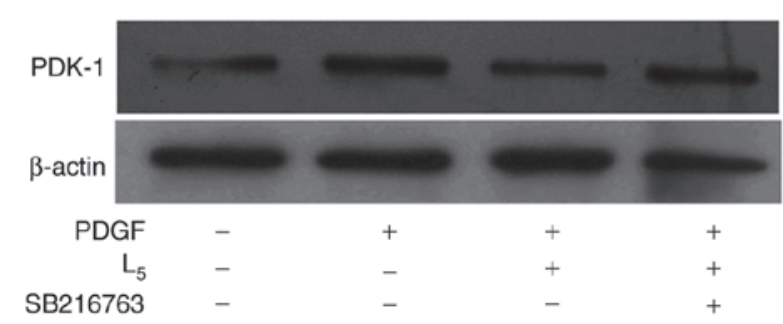

B

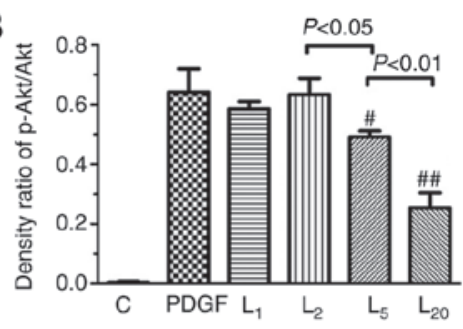

D

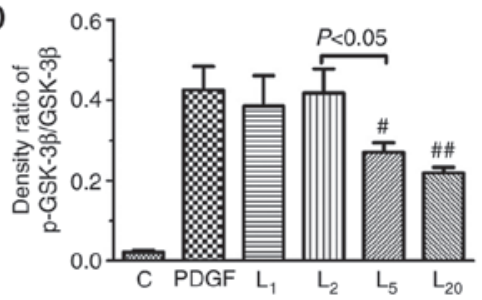

$F$
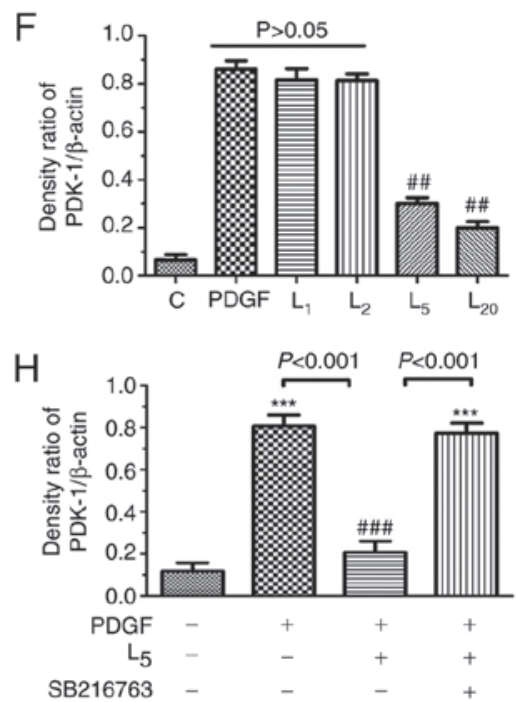

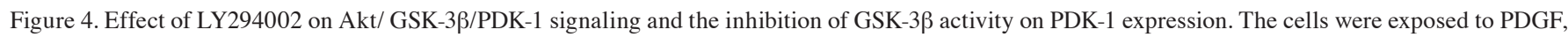
or with increasing LY294002 concentrations of 1,2,5 and $20 \mu \mathrm{M}$ for $24 \mathrm{~h}$, prior to detection of the expression of (A and B) p-Akt, (C and D) GSK-3 $\beta$ or (E and F) PDK-1. (G and H) The cells were treated with PDGF, or with $5 \mu \mathrm{M} \mathrm{LY} 294002$ with/without 30 min pre-exposure to $5 \mu \mathrm{M} \mathrm{SB} 216763$ for $24 \mathrm{~h}$, prior to the detection of PDK-1 expression. ${ }^{\#} \mathrm{P}<0.05$ and ${ }^{\# \#} \mathrm{P}<0.01$ vs. cells treated with PDGF. ${ }^{* * *} \mathrm{P}<0.001$ vs. control cells. Results were pooled from three separate experiments and are presented as mean \pm standard deviation. A, C and E are the representative change of p-Akt or p-GSK-3 $\beta$ and PDK-1 expression, respectively. The representative change of one of the three experiments is presented, as all assays exhibited identical results. Semi-quantitative analyses of p-Akt, p-GSK-3 $\beta$ and PDK-1 expression levels are presented in B, D, F and H, respectively. C, control; PDGF, platelet-derived growth factor; L1, L2, L5 and L10, cells treated with LY294002 at 1, 2, 5 and $20 \mu \mathrm{M}$ following PDGF exposure; Akt, protein kinase B; GSK-3 $\beta$, glycogen synthase kinase-3 $\beta$; PDK-1, pyruvate dehydrogenase kinase-1; p-, phosphorylated.

in the downregulation of PDK-1 by LY294002, PASMCs were treated with a GSK-3 $\beta$ inhibitor $(5 \mu \mathrm{M}$ SB216763) for $30 \mathrm{~min}$ prior to PDGF-BB and $5 \mu \mathrm{M}$ LY294002 exposure for $24 \mathrm{~h}$. The inhibitory effect of LY294002 on PDK-1 was completely abrogated by SB216763 (Fig. 4G-H).

\section{Discussion}

The hyperplasia of PASMCs within the vascular wall of distal pulmonary arterioles, causing medial hypertrophy and neointimal lesion formation, is a hallmark of pulmonary vascular remodelling in PAH (2). Abnormality in energy metabolism is one of the contributing factors that results in aberrant growth of PASMCs $(21,22)$. In accordance with previous studies in cancer cell lines $(23,24)$, DCA in the present study inhibited human PASMC proliferation stimulated by
PDGF in a dose-dependent manner (0-50 mM). Reversal of the Warburg effect by downregulating PDK-1 and HIF-1 $\alpha$ and inactivation of HK-2 may account for the repression of the aberrant growth of human PASMCs treated by DCA. Notably, the pro-apoptotic effect of DCA may also be potentiated by the inhibition of PDK-1, PDH phosphorylation and HK-2 inactivity through blocking Akt/GSK-3 $\beta / \mathrm{HIF}-1 \alpha$ signalling with a PI3K inhibitor.

Accumulating evidence has suggested that PDGF was highly expressed in the neointimal lesions of pulmonary arterioles from rats subjected to monocrotaline or hypoxia insult $(5,25)$. Targeting of the PDGF receptor using imatinib exhibited beneficial effects on PASMC proliferation and mitigated the neointimal formation of the affected pulmonary arterioles. Repression of PDGF receptor phosphorylation and subsequent mitogen activated protein kinase activation underlies the alleviation of $\mathrm{PAH}$ 
by imatinib (5), but the precise mechanism remains unclear. A previous study from Xiao et al (7) provided novel insights into the current understanding of PDGF-induced PASMC proliferation. Consistent with the mitochondrial metabolic shifting paradigm in cancer (26), PDGF induced increased expression of a glycolysis-associated gate-keeper enzyme PDK-1, glucose transporter-1 and HIF-1 $\alpha$, preferentially converting pyruvate to lactate in PASMCs (7). DCA selectively inhibits PDK activity, thereby indirectly inactivating $\mathrm{PDH}$ and shifting metabolism to mitochondrial glucose oxygenation, thereby reversing apoptotic resistance; this change has been demonstrated to be important in attenuating PASMCs hyperplasia in several rodent models of PAH $(9,27)$. Consistent with these studies, the results of the present study suggested that a high dose of DCA facilitated the reversal of PASMCs glycolytic status, which was confirmed by decreased lactate content in culture medium. Along with rectifying this abnormal glycolysis metabolism phenotype, DCA treatment promoted apoptotic sensitivity and inhibited proliferation of PASMCs.

One notable result from the present study was that the inhibitory effect of DCA on PASMCs growth was potentiated by blocking the PI3K/Akt signalling pathway. Although $5 \mu \mathrm{M}$ LY294002 exhibited a negligible effect on cell apoptosis, it increased caspase-3 levels and promoted apoptosis in PASMCs treated with $10 \mathrm{mM}$ DCA. Previous studies demonstrated that the median lethal dose of DCA causing growth retardation in human cancer cell lines was 5-20 mM (28-30). DCA has a relatively wide therapeutic margin, and few adverse reactions have been described, even following long-term ingestion, with the exception of a few case reports of peripheral nerve lesions (31). However, a previous study suggested that the incubation of rat sciatic nerves with $20 \mathrm{mM}$ DCA caused a $15 \%$ decrease in the amplitude of the compound action potential, while $10 \mathrm{mM}$ DCA had no effect on the nerve transduction (32). Therefore, combined pharmaceutical intervention is recommended to avoid a potential adverse reaction due to overdose by single drug use, as multiple studies have indicated that the anti-tumour effect of DCA may be improved by sensitising the pro-apoptotic signalling pathway in cancer cell lines $(33,34)$.

The results of the present study indicated that the reversal of the Warburg effect mediated through the downregulation of HIF- $1 \alpha$ and inactivation of HK-2 may account for the increased PASMC apoptosis following DCA intervention. DCA is a well-characterised inhibitor of the protein kinase PDH. DCA-mediated inhibition of PDKs triggers a switch in pyruvate metabolism towards glucose oxidation to $\mathrm{CO}_{2}$ in the mitochondria; during the process of electron transport in the Krebs cycle, the intermediate substrates (mitochondrial reactive oxygen species or $\alpha$-ketoglutarate) serve key roles in the destabilisation of HIF-1 $\alpha$, which also reverses hyper-polarised

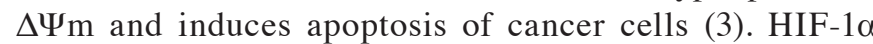
upregulation was also demonstrated by Lambert et al (12), in a rodent model with carotid arterial neointimal formation induced by balloon injury. Targeting HIF-1 $\alpha$ using siRNA effectively reversed the aerobic glycolysis of SMCs and mitigated the neointimal lesions in diseased carotid arteries. In Fawn-Hooded rats, DCA inhibited proliferation of PASMCs by reversing the mitochondrial metabolic phenotype and inactivation of HIF-1 $\alpha$ and downstream voltage-gated potassium channel subtype 1.5 (27). HK-2 has been recognised as one of the key molecules in cell proliferation, differentiation and metastasis during carcinogenesis: Inhibition of HK-2 using 2-DG or siRNA exhibited beneficial effects on tumour growth in a xenograft model $(35,36)$. However, the role of HK-2 in DCA-induced PASMC apoptosis remains unclear. Previous studies indicated that the HK-2 gene promoter comprising a 5'-RCGTG-3' box known as the hypoxia response element was under precise transcriptional regulation by HIF-1 $\alpha$ (37). HIF-1 $\alpha$ activation was demonstrated to serve a critical role in the subsequent upregulation of $\mathrm{HK}-2$ in diverse cancer cells, but has rarely been described in vascular cells, particularly in PASMCs. The present study indicated that with the downregulation of HIF-1 $\alpha$ following DCA treatment, the expression and activity of HK-2 decreased. Therefore, the present results suggested that HIF- $1 \alpha$ induced HK-2 activation in the apoptotic-resistant PASMCs. Consistent with previous studies $(12,20)$, these data indicated that in addition to HK-2 downregulation, the dislocation of HK-2 from VDAC on the mitochondrial outer membrane was involved in cell apoptosis following DCA treatment, which was associated with an efflux of cytochrome $c$ into the cytoplasm and caspase-3 activation. However, although there was no significant difference in the expression levels of cleaved caspase- 3 in cells treated with 10 mM DCA alone or a combination of LY294002 and DCA, the number apoptotic cells was markedly increased in the combined treatment group. We hypothesize that the activation of PI3K/Akt signalling is associated with the cytosolic sequestration of the apoptotic protein B-cell lymphoma 2 (Bcl-2)-associated death protein (BAD); therefore, pharmaceutic ablation of PI3K facilitates BAD translocation with B-cell lymphoma-extra large on the outer membrane of the mitochondria, which activates caspase-9 and -3 and causes the opening of the mitochondrial membrane transit pore (MTP). In addition to the release of cytochrome $c$ following the MTP opening, the apoptotic inducing factor may also be released into the cytoplasm. The latter may initiate the non-caspase-3-dependent apoptosis pathway.

PDK-1 has been proposed as a key regulator of the Warburg effect and inhibits acetyl-CoA entry into the Krebs cycle, accompanied with decreased ketoglutarate synthesis, leading to decreased HIF-1 $\alpha$ proteasomal degradation (38). DCA is a pyruvate mimetic that targets PDKs, inhibiting the phosphorylation of PDH (31). Therefore, we hypothesised that inhibiting the activity of PDK-1 promoted the degradation of HIF-1 $\alpha$ and rectified the pseudo-hypoxic status in mitochondria of PASMCs exposed to PDGF followed by DCA treatment. In addition, the results of the present study suggested that DCA inhibited PDK-1 expression in addition to downregulating PDK-1 activity. The mechanism of the DCA-induced decrease in PDK-1 is poorly delineated, and we postulate that PDK-1 activation induces a pseudo-hypoxic state in mitochondria and HIF- $1 \alpha$ activation, while HIF- $1 \alpha$ inhibits the tricarboxylic acid cycle by directly activating the gene encoding PDK-1, which initiates a positive regulatory loop. The results of the present study suggested that DCA inhibits PDK-1 activity and disrupts the vicious cycle among aerobic glycolysis-associated molecules, accounting for the decreased expression of PDK-1 in PASMCs. A previous study indicated that the activation of PDGF receptor increased PDK-1 activity, mitochondrial respiration and cell proliferation (7); however, the effect of 
PI3K suppression on PDK-1 and its target molecule (PDH) in growth factor receptor tyrosine kinase-induced glycolytic flux remains unclear (39). Several previous data indicate that the PI3K/Akt/HIF-1 $\alpha$ axis serves an essential role in PDGF-induced vascular SMC proliferation mediated through enhanced glycolytic flux $(7,12)$. Inhibition of PI3K decreases extracellular acidification rates through HIF-1 $\alpha$ downregulation in vascular SMCs stimulated with growth factors (40). PDK-1 downregulation with LY294002 was abrogated by the GSK-3 $\beta$ inhibitor in the present study; therefore, the downregulation of HIF- $1 \alpha$ by GSK-3 $\beta$ signal blockade is the key factor responsible for disrupting the mutual positive feedback regulation between HIF- $1 \alpha$ and PDK-1 when co-incubated with DCA. In contrast to the results of the present study, PI3K blockade with LY294002 facilitated the phosphorylation of PDH at the E1 $\alpha$-subunit (inactivation of its function) and decreased the oxygen consumption rate in SQ20B cells (41). Therefore, the role of PI3K/Akt activation in regulation of downstream signals of glycolysis-associated enzymes varies among diverse cells.

There are certain limitations in the present study to be addressed: Firstly, with the exception of GSK-3 $\beta$, other downstream molecules of Akt, including mechanistic target of rapamycin, may be affected following PI3K/Akt signal blocking (42), which is closely associated with cell survival and autophagy, and may have potential effects on PASMCs apoptosis. Therefore, the possibility that other signal molecules may be involved in the DCA-induced decrease in cell growth cannot not be excluded. Secondly, LY-294002 may also affect cell cycle proteins, including cyclin-dependent kinases, and DCA was indicated to inhibit cell cycle progression, had no association with cell apoptosis and inhibited cell hyperplasia in certain cell lines (43). Therefore, the synergistic effect of DCA and PI3K blockade on PASMC growth may be mediated by cell cycle suppression, and additional studies are warranted.

Collectively, the data in the present study indicated that the pro-apoptotic effect of DCA on human PASMCs was associated with PDK-1 and HIF-1 $\alpha$ downregulation, which led to HK-2 inactivation by blocking the interaction with mitochondria. Furthermore, this effect may be potentiated by the suppression of PDK-1 via blockade of Akt/GSK-3 $\beta / \mathrm{HIF}-1 \alpha$ signalling. These results suggest that the inhibition of Akt/GSK-3 $\beta$ signalling may improve the pro-apoptotic effect of DCA on human PASMCs, which suggests that combined therapy may be used in the treatment of PAH and may decrease the probability of peripheral neuropathic lesions or liver damage following long-term ingestion of high doses of DCA.

\section{Acknowledgements}

The authors would like to thank Dr Yong Liu for his technical support in fluorescence activated cell sorting detection for cell apoptosis.

\section{Funding}

The present study was supported by National Natural Science Foundation of China (project no., 81470242), the Six Talent Summit Project of Jiangsu Province (project no., WSN-147) and the Medical Science and Technique Development Foundation of Nanjing Municipal Government (grant no., RX17013).

\section{Availability of data and materials}

All data generated or analyzed during this study are included in this published article.

\section{Authors' contributions}

BL and JY contributed to experimental design, performed experiments, data analysis and wrote the final manuscript. YZ, QS, LC, YT and CY performed experiments and contributed to preparation of the manuscript. All authors read and approved the final manuscript.

\section{Ethics approval and consent to participate}

The approval of this study was obtained from the ethic committee of Drum tower Hospital of Nanjing University Medical School for Laboratory Animal Use and Care.

\section{Patient consent for publication}

Not applicable.

\section{Competing interests}

The authors declare that they have no competing interests.

\section{References}

1. Gurtu V and Michelakis ED: Emerging therapies and future directions in pulmonary arterial hypertension. Can J Cardiol 31: 489-501, 2015.

2. Tuder RM: Pathology of pulmonary arterial hypertension. Semin Respir Crit Care Med 30: 376-385, 2009.

3. Michelakis ED, Webster L and Mackey JR: Dichloroacetate (DCA) as a potential metabolic-targeting therapy for cancer. Br J Cancer 99: 989-994, 2008.

4. Paulin R and Michelakis ED: The metabolic theory of pulmonary arterial hypertension. Circ Res 115: 148-164, 2014.

5. Schermuly RT, Dony E, Ghofrani HA, Pullamsetti S, Savai R, Roth M, Sydykov A, Lai YJ, Weissmann N, Seeger W, et al: Reversal of experimental pulmonary hypertension by PDGF inhibition. J Clin Invest 115: 2811-2821, 2005.

6. Berghausen E, ten Freyhaus H and Rosenkranz S: Targeting of platelet-derived growth factor signaling in pulmonary arterial hypertension. Handb Exp Pharmacol 218: 381-408, 2013.

7. Xiao Y, Peng H, Hong C, Chen Z, Deng X, Wang A, Yang F, Yang L, Chen C and Qin X: PDGF promotes the warburg effect in pulmonary arterial smooth muscle cells via activation of the PI3K/AKT/mTOR/HIF-1 $\alpha$ signaling pathway. Cell Physiol Biochem 42: 1603-1613, 2017

8. Rehman J and Archer SL: A proposed mitochondrial-metabolic mechanism for initiation and maintenance of pulmonary arterial hypertension in fawn-hooded rats: The Warburg model of pulmonary arterial hypertension. Adv Exp Med Biol 661: 171-185, 2010.

9. McMurtry MS, Bonnet S, Wu X, Dyck JR, Haromy A, Hashimoto K and Michelakis ED: Dichloroacetate prevents and reverses pulmonary hypertension by inducing pulmonary artery smooth muscle cell apoptosis. Circ Res 95: 830-840, 2004.

10. Guignabert C, Tu L, Izikki M, Dewachter L, Zadigue P, Humbert M, Adnot S, Fadel E and Eddahibi S: Dichloroacetate treatment partially regresses established pulmonary hypertension in mice with SM22alpha-targeted overexpression of the serotonin transporter. FASEB J 23: 4135-4147, 2009. 
11. Michelakis ED, McMurtry MS, Wu XC, Dyck JR, Moudgil R, Hopkins TA, Lopaschuk GD, Puttagunta L, Waite R and Archer SL: Dichloroacetate, a metabolic modulator, prevents and reverses chronic hypoxic pulmonary hypertension in rats: Role of increased expression and activity of voltage-gated potassium channels. Circulation 105: 244-250, 2002.

12. Lambert CM, Roy M, Robitaille GA, Richard DE and Bonnet S: HIF-1 inhibition decreases systemic vascular remodelling diseases by promoting apoptosis through a hexokinase 2-dependent mechanism. Cardiovasc Res 88: 196-204, 2010.

13. Semenza GL: Hypoxia-inducible factor 1: Oxygen homeostasis and disease pathophysiology. Trends Mol Med 7: 345-350, 2001.

14. Wilson JE: Isozymes of mammalian hexokinase. Structure, subcellular localization and metabolic function. J Exp Biol 206: 2049-2057, 2003.

15. Pastorino JG and Hoek JB: Hexokinase II: The integration of energy metabolism and control of apoptosis. Curr Med Chem 10: 1535-1551, 2003.

16. Yasuda S, Arii S, Mori A, Isobe N, Yang W, Oe H, Fujimoto A, Yonenaga Y, Sakashita $\mathrm{H}$ and Imamura M: Hexokinase II and VEGF expression in liver tumors: Correlation with hypoxia-inducible factor 1 alpha and its significance. J Hepatol 40: 117-123, 2004.

17. Riddle SR, Ahmad A, Ahmad S, Deeb SS, Malkki M, Schneider BK, Allen CB and White CW: Hypoxia induces hexokinase II gene expression in human lung cell line A549. Am J Physiol Lung Cell Mol Physiol 278: L407-L416, 2000.

18. Yan J, Shen Y, Wang Y and Li BB: Increased expression of hypoxia-inducible factor- $1 \alpha$ in proliferating neointimal lesions in a rat model of pulmonary arterial hypertension. Am J Med Sci 345: 121-128, 2013.

19. Zhuo B, Li Y, Li Z, Qin H, Sun Q, Zhang F, Shen Y, Shi Y and Wang R: PI3K/Akt signaling mediated Hexokinase-2 expression inhibits cell apoptosis and promotes tumor growth in pediatric osteosarcoma. Biochem Biophys Res Commun 464: 401-406, 2015.

20. Bonnet S, Paulin R, Sutendra G, Dromparis P, Roy M, Watson KO, Nagendran J, Haromy A, Dyck JR and Michelakis ED: Dehydroepiandrosterone reverses systemic vascular remodeling through the inhibition of the Akt/GSK3-\{beta\}/NFAT axis Circulation 120: 1231-1240, 2009.

21. Dromparis P, Sutendra G and Michelakis ED: The role of mitochondria in pulmonary vascular remodeling. J Mol Med 88 1003-1010, 2010

22. Assad TR and Hemnes AR: Metabolic dysfunction in pulmonary arterial hypertension. Curr Hypertens Rep 17: 20, 2015.

23. Haugrud AB, Zhuang Y, Coppock JD and Miskimins WK Dichloroacetate enhances apoptotic cell death via oxidative damage and attenuates lactate production in metformin-treated breast cancer cells. Breast Cancer Res Treat 147: 539-550, 2014.

24. Allen KT, Chin-Sinex H, DeLuca T, Pomerening JR, Sherer J, Watkins JB III, Foley J, Jesseph JM and Mendonca MS: Dichloroacetate alters Warburg metabolism, inhibits cell growth, and increases the X-ray sensitivity of human A549 and H1299 NSC lung cancer cells. Free Radic Biol Med 89: 263-273, 2015.

25. Antoniu SA: Targeting PDGF pathway in pulmonary arterial hypertension. Expert Opin Ther Targets 16: 1055-1063, 2012.

26. Peng H, Xiao Y, Deng X, Luo J, Hong $C$ and Qin X: The Warburg effect: A new story in pulmonary arterial hypertension. Clin Chim Acta 461: 53-58, 2016

27. Bonnet S, Michelakis ED, Porter CJ, Andrade-Navarro MA, Thébaud B, Bonnet S, Haromy A, Harry G, Moudgil R, McMurtry MS, et al: An abnormal mitochondrial-hypoxia inducible factor-1alpha-Kv channel pathway disrupts oxygen sensing and triggers pulmonary arterial hypertension in fawn hooded rats: Similarities to human pulmonary arterial hypertension. Circulation 113: 2630-2641, 2006.
28. Wong JY, Huggins GS, Debidda M, Munshi NC and De Vivo I: Dichloroacetate induces apoptosis in endometrial cancer cells. Gynecol Oncol 109: 394-402, 2008

29. Madhok BM, Yeluri S, Perry SL, Hughes TA and Jayne DG: Dichloroacetate induces apoptosis and cell-cycle arrest in colorectal cancer cells. Br J Cancer 102: 1746-17521, 2010.

30. Sun RC, Board PG and Blackburn AC: Targeting metabolism with arsenic trioxide and dichloroacetate in breast cancer cells. Mol Cancer 10: 142, 2011.

31. Stacpoole PW, Nagaraja NV and Hutson AD: Efficacy of dichloroacetate as a lactate-lowering drug. J Clin Pharmacol 43 683-691, 2003.

32. Kagiava A and Theophilidis G: High concentrations of dichloroacetate have minor effects on the vitality of the mammalian nerve fibers: An ex-vivo electrophysiological study. Anticancer Drugs 22: 273-276, 2011.

33. Cao W, Yacoub S, Shiverick KT, Namiki K, Sakai Y, Porvasnik S, Urbanek C and Rosser CJ: Dichloroacetate (DCA) sensitizes both wild-type and over expressing Bcl-2 prostate cancer cells in vitro to radiation. Prostate 68: 1223-1231, 2008

34. Tong J, Xie G,He J,Li J,Pan F and Liang H: Synergistic antitumor effect of dichloroacetate in combination with 5-fluorouracil in colorectal cancer. J Biomed Biotechnol 2011: 740564, 2011.

35. Wang H, Wang L, Zhang Y, Wang J, Deng Y and Lin D: Inhibition of glycolytic enzyme hexokinase II (HK2) suppresses lung tumor growth. Cancer Cell Int 16: 9, 2016.

36. Ahn KJ, Hwang HS, Park JH, Bang SH, Kang WJ, Yun M and Lee JD: Evaluation of the role of hexokinase type II in cellular proliferation and apoptosis using human hepatocellular carcinoma cell lines. J Nucl Med 50: 1525-1532, 2009.

37. Masoud GN and Li W: HIF-1 $\alpha$ pathway: Role, regulation and intervention for cancer therapy. Acta Pharm Sin B 5: 378-389, 2015.

38. Semenza GL: HIF-1: Upstream and downstream of cancer metabolism. Curr Opin Genet Dev 20: 51-56, 2010.

39. Velpula KK, Bhasin A, Asuthkar S and Tsung AJ: Combined targeting of PDK1 and EGFR triggers regression of glioblastoma by reversing the Warburg effect. Cancer Res 73: 7277-7289, 2013.

40. Perez J, Hill BG, Benavides GA, Dranka BP and Darley-Usmar VM: Role of cellular bioenergetics in smooth muscle cell proliferation induced by platelet-derived growth factor. Biochem J 428: 255-267, 2010.

41. Cerniglia GJ,Dey S, Gallagher-Colombo SM, Daurio NA, Tuttle S, Busch TM, Lin A, Sun R, Esipova TV, Vinogradov SA, et al: The PI3K/Akt pathway regulates oxygen metabolism via pyruvate dehydrogenase (PDH)-E1 $\alpha$ phosphorylation. Mol Cancer Ther 14: 1928-1938, 2015.

42. Yang X, Cheng Y, Li P, Tao J, Deng X, Zhang X, Gu M, Lu Q and Yin C: A lentiviral sponge for miRNA-21 diminishes aerobic glycolysis in bladder cancer T24 cells via the PTEN/PI3K/AKT/mTOR axis. Tumour Biol 36: 383-391, 2015.

43. Delaney LM, Ho N, Morrison J, Farias NR, Mosser DD and Coomber BL: Dichloroacetate affects proliferation but not survival of human colorectal cancer cells. Apoptosis 20: 63-74, 2015.

This work is licensed under a Creative Commons Attribution-NonCommercial-NoDerivatives 4.0 International (CC BY-NC-ND 4.0) License. 